--Manuscript Draft--

\begin{tabular}{|c|c|}
\hline Manuscript Number: & COGSC-D-19-00022R1 \\
\hline Article Type: & 21: New Synthetic Methods (2020) \\
\hline Short Title: & Bio-based and biodegradable polymers \\
\hline Corresponding Author's Institution: & University of Dublin Trinity College \\
\hline Corresponding Author E-Mail: & BABUP@tcd.ie \\
\hline First Author: & Saranya Rameshkumar \\
\hline \multirow{2}{*}{ Order of Authors: } & Kevin E O'Connor \\
\hline & Ramesh Babu P, PhD \\
\hline Abstract: & $\begin{array}{l}\text { Frontiers of bio-based and biodegradable polymers are constantly expanding in a view } \\
\text { to achieve sustainability. Hence, designing sustainable bioplastics made of either bio- } \\
\text { based or biodegradable polymers opens up opportunities to overcome resource } \\
\text { depletion and plastic pollution. This review presents a broad perspective on state-of- } \\
\text { the-art technologies in bioplastics manufacturing along with the challenges underlying } \\
\text { its production, application and post-consumer waste management. Recent scientific } \\
\text { advances are catalysing the sustainable design of bioplastics to overcome the present } \\
\text { challenges of plastic waste and emerging end-of-life options are contributing to circular } \\
\text { economy. As research insights on developing sustainable bioplastics are rapidly } \\
\text { evolving, its production and waste management approaches are not only confined to } \\
\text { those discussed in this review. }\end{array}$ \\
\hline
\end{tabular}


$5^{\text {th }}$ December 2019

To

\section{The Editor,}

\section{Current Opinion in Green and Sustainable Chemistry}

Elsevier Publications

Dear Fabio Arico,

\section{Sub: Submission of revised manuscript- COGSC-D-19-00022-Reg.}

Thank you for reviewer's comments and we have addressed comments made by the Reviewer 2 and specific changes made in the manuscript are highlighted in Red in the revised version. All the editorial corrections suggested were incorporated in the revised version. Hope the revised manuscript meet the requirements COGSC for publication.

\section{Reviewer 2:}

The article highlights effectively currently available strategies for production and management of the most common types of bio-based plastics and partially bio-based ones. Although it deserves to be published on "Current Opinion in Green and Sustainable Chemistry", as it stands the manuscript requires some extensive revision as listed below and in the attached PDF file

Page 1: when discussing the yearly production volumes of PHAs compared to PBS and PBAT, please add some relevant updated figures on production.

Authors Response: We have included the updated figures on global production volumes to compare PHA with PBS and PBAT as per recent European Bioplastics market report with relevant citation.

Page 2, Figure 1: this figure is unclear, in particular the bottom part displaying "innovative bioplastics". Please clarify: is it a list of applications? Are these applications specific for the different types of bioplastics? If so, this should be highlighted in the figure. 
Authors Response: Figure 1 has been modified in the revised manuscript. We intend to mention that there are emerging avenues of developing novel bioplastics by synergistically combining bio-based and biodegradable polymers for various applications.

Page 5, Table 1: this table is adapted from one of the references reported? If so, it should be added in the table caption.

Authors Response: Yes, information mentioned in Table 1 was adapted from reference [17] and the same reference is included in Table caption.

Page 7: when discussing the BBI competitive co-funding scheme from the European Commission, please provide some relevant, updated figures on the program. Additionally, please avoid discussing ongoing project (e.g. AgriChemWhey, which is due for completion in 2021).

Authors Response: Relevant updated figures regarding BBI consortium has now been included revised manuscript and as per reviewer's suggestion, any information related to the ongoing projects has been removed.

Page 7: when discussing $\mathrm{CO}_{2}$ chemical conversion strategies for the production of polycarbonates, please add some figures. Although it is a $\mathrm{CO}_{2}$ valorization strategy, it will have limited impact on $\mathrm{CO}_{2}$ mitigation compared to synthesis of $\mathrm{CO}_{2}$ based inorganic materials. Authors Response: We have added relevant figures on $\mathrm{CO}_{2}$ content in bio-based polycarbonates and the expected production demand of plastics made from $70 \%$ direct $\mathrm{CO}_{2}$ have been included in the revised manuscript to highlight the significance of $\mathrm{CO}_{2}$ upcycling strategies. 


\section{Conflict of Interest and Authorship Conformation Form}

Please check the following as appropriate:

- All authors have participated in (a) conception and design, or analysis and interpretation of the data; (b) drafting the article or revising it critically for important intellectual content; and (c) approval of the final version.

- This manuscript has not been submitted to, nor is under review at, another journal or other publishing venue.

- The authors have no affiliation with any organization with a direct or indirect financial interest in the subject matter discussed in the manuscript

- The following authors have affiliations with organizations with direct or indirect financial interest in the subject matter discussed in the manuscript:

Author's name

Affiliation

\begin{tabular}{ll}
\hline Ramesh Babu P & Trinity College Dublin \\
\hline Saranya Rameshkumar & Trinity College Dublin \\
\hline Shaiju Parameswaran & Trinity College Dublin \\
\hline Kevin O'Connor & University College Dublin \\
\hline & \\
\hline
\end{tabular}




\title{
Bio-based and biodegradable polymers - State-of-the-art, Challenges and Emerging
} Trends

\author{
Saranya Rameshkumar ${ }^{a}, P$. Shaiju ${ }^{a}$, Kevin E O'Connor ${ }^{c, d}$ and Ramesh Babu $P^{a, b, c^{*}}$ \\ ${ }^{a}$ AMBER, CRANN Institute, Trinity College Dublin, Dublin 2, Republic of Ireland \\ ${ }^{b}$ School of Chemistry, Trinity College Dublin, Dublin 2, Republic of Ireland \\ ${ }^{c}$ BEACON - Bioeconomy Research centre, University College Dublin, Belfield, Dublin 4, \\ Republic of Ireland \\ ${ }^{d}$ Earth Institute, University College Dublin, Belfield Campus, D4, Dublin, Republic of Ireland \\ *Corresponding Author-E-mail: babup@tcd.ie
}

\begin{abstract}
:
Frontiers of bio-based and biodegradable polymers are constantly expanding in a view to achieve sustainability. Hence, designing sustainable bioplastics made of either bio-based or biodegradable polymers opens up opportunities to overcome resource depletion and plastic pollution. This review presents a broad perspective on state-of-the-art technologies in bioplastics manufacturing along with the challenges underlying its production, application and post-consumer waste management. Recent scientific advances are catalysing the sustainable design of bioplastics to overcome the present challenges of plastic waste and emerging end-oflife options are contributing to circular economy. As research insights on developing sustainable bioplastics are rapidly evolving, its production and waste management approaches are not only confined to those discussed in this review.
\end{abstract}

\section{Introduction and market growth}

$21^{\text {st }}$ century is thriving with tremendous economic growth but at the same time facing an irrecoverable ecological damage. Plastic pollution is recently being highlighted as global crisis at every stage right from its production to disposal and incineration [1]. Bioplastics constituting both naturally and chemically derived materials from renewable or oil-based resources are being designed to feature minimal carbon footprint, high recycling value and complete biodegradability/compostability [2,3]. In order to ascertain no competition with food and agriculture resources, recent advancements are emerging to develop next-generation bioplastics derived from renewable waste streams, microbial/microalgal cells and biomass which eventually fosters carbon neutral infrastructure for bioplastics production and management [4, 5]. Moreover, sustainable production and recycling mechanisms for 
bioplastics are considered to have huge compliance with the policies/actions set by United Nation's Sustainability development goals (UN SDGs) and European circular economy strategy [6].

The global bioplastics production capacities are difficult to estimate and are usually based on forecast due to continuously emerging range of bio-based and biodegradable polymers and rising interests on investing in bioplastics sector. Recent report published by Nova-Institute has predicted that global bioplastics production capacity growing at a considerable pace from around 2.11 million tonnes in 2018 to 2.62 million tonnes in 2023 [7]. Europe ranks top in the research and development of bioplastics and stands next to Asia as major hub for bioplastics production and consumption [8]. With many innovative bioplastics entering the market segments for diversified applications, industries are interested in expanding the production capacity. Acute relevance to sustainability and circular economy has been indeed influencing the bioplastics industry to achieve substantial growth, technological maturity with multiple production routes.

\section{Progress and trends in commercial bioplastics}

Naturally occurring polymers like cellulose derivatives, thermoplastic starch (TPS) and their blends stands highest in terms of production capacity as these materials are replacing plastics particularly in flexible film packaging sector $[9,10]$. Recent bioplastics market update shows that polylactic acid (PLA) receives greater attention from both academia and industry due to its technological advances productivity and functionality $[11,12]$. PLA is a known for its versatility featuring excellent barrier properties thus gaining value to replace polystyrene (PS) and polypropylene (PP) in packaging and other challenging applications [13]. Next to PLA, polyhydroxy alkanoates (PHA) receives interest as evidenced by greater number of international patents [14]. However, in terms of global production capacity, PHA stands next to poly (butylene adipate-coterephthalate (PBAT) and polybutylene succinate (PBS). As per recent market report, current global production of PHA is about 25,320 tonnes, which accounts to $1.2 \%$ as against PBAT and PBS holding $13.4 \%$ and $4.3 \%$ respectively [15]. Polycaprolactone (PCL) and PBAT are fossil-based polymers but tend to biodegrade, signifying that biodegradability is not always dependent on its source of origin or the polymer building block. Schematic representation shown in Figure 1 clearly demarcates various technological approaches specific to different classes of bioplastics. 


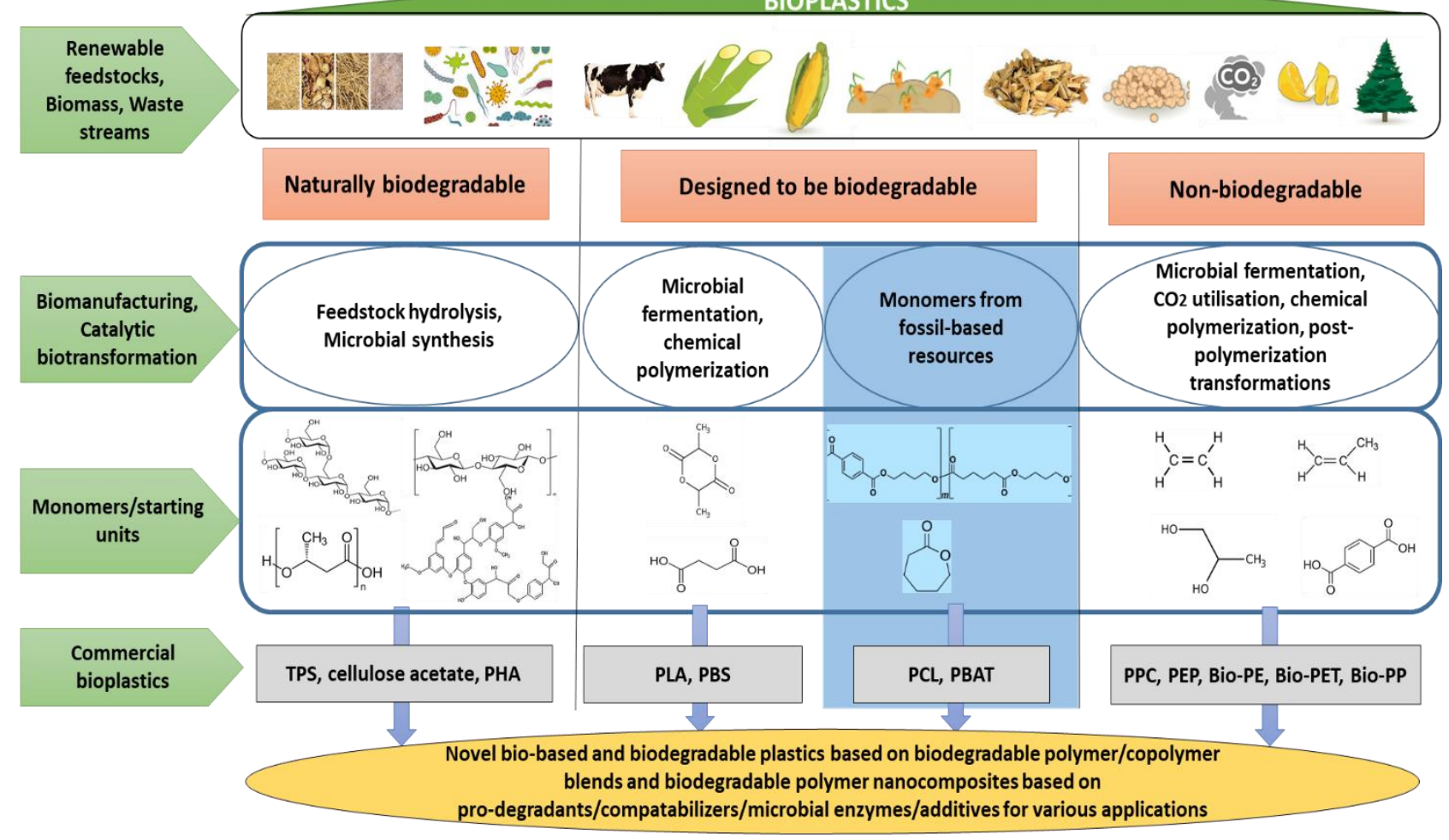

Figure 1. Schematic representation of technological approaches in producing commercial bioplastics (Shaded in blue-Biodegradable polymers derived from oil-based resources)

Majorly used commodity polymers like polyethylene terephthalate, polyamide and polypropylene have also been manufactured from bio monomers derived glucose fermentation or lignin fermentation which facilitates the resurgence of Bio-PET, Bio-PA, Bio-PP respectively [16]. Growing interest in novel bioplastics constituting two or more existing biodegradable polymers would eventually result in second-generation bioplastics, thus offering advantage of developing scalable counterparts to synthetic plastics [17]. Hence, the goal would be to design novel composites comprising only of bio-based building blocks having specific desired functionalities suitable for applications and at the same time completely biodegradable and recyclable building blocks having specific desired functionalities suitable for technological applications [18]. For example, in a recent work, synergic blends of PLA and PCL were highlighted as completely biodegradable (in domestic composting conditions) alternatives to conventional, petrochemical based plastics [19]. Emerging bio-based polymers like Poly (Ethylene 2, 5-Furandicarboxylate) (PEF)/ poly (trimethylene terephthalate) (PTT) and polypropylene carbonate (PPC) produced from bio-based furan monomers and alcohols/epoxides respectively are characterized by excellent thermal and barrier properties 
comparable to its petroleum analogues [20]. For instance, blending PEF with PLA or PHA would ultimately contribute to superior functional and biodegradable properties enabling practical application in packaging applications [21]. The trade-off between biodegradability and functionality brings huge research scope on blending and compatibilization of various biobased polymers to push its performance efficiency and versatility [22, 23]. Table 1 shows the widely known bio-based and biodegradable and their respective starting materials and feasible end-of-life options $[18,24]$.

Table 1: Commercial bioplastics including both biodegradable and non-biodegradable polymers, its production source, capacity and end-of-life options (Adapted and modified from [18])

\section{Biodegradable polymers}

\begin{tabular}{|c|c|c|c|c|}
\hline Polymer Name & Source/Feedstock & $\begin{array}{c}\text { Production } \\
\text { capacity } \\
\text { (Kt/Year) }\end{array}$ & Trademark/Company & $\begin{array}{c}\text { Sustainable end- } \\
\text { of-life options }\end{array}$ \\
\hline $\begin{array}{c}\text { TPS, Cellulose, } \\
\text { Cellulose acetate, } \\
\text { Starch blends }\end{array}$ & $\begin{array}{c}\text { Biomass, agro- } \\
\text { residues, } \\
\text { lignocellulosic } \\
\text { derivatives }\end{array}$ & 384 & $\begin{array}{c}\text { Mater-Bi/Novamont, } \\
\text { Agrana starke, } \\
\text { NaturePlast, Indochine } \\
\text { Bio Plastiques }\end{array}$ & $\mathrm{HC}, \mathrm{IC}, \mathrm{AD}$ \\
\hline $\begin{array}{l}\text { PLA \& PLA } \\
\text { blends }\end{array}$ & $\begin{array}{l}\text { Lactic acid from dairy } \\
\text { whey, corn starch or } \\
\text { organic residues }\end{array}$ & 225 & $\begin{array}{c}\text { Ingeo/NatureWorks, } \\
\text { Luminy®/Total Corbion, } \\
\text { Lacty/Shimadzu Cor. } \\
\text { Vyloecol/Toyobo, } \\
\text { Danimer Scientific }\end{array}$ & $\mathrm{IC}, \mathrm{MR}, \mathrm{CR}$ \\
\hline PHA, PHB, PHO & $\begin{array}{l}\text { Volatile fatty acids, } \\
\text { glucose/glycerol from } \\
\text { fermentation of } \\
\text { municipal solid waste } \\
\text { or any carbon } \\
\text { feedstocks }\end{array}$ & 30 & $\begin{array}{c}\text { Minerv-PHA }{ }^{\mathrm{TM}} / \text { Bio-On, } \\
\text { PHBH }^{\mathrm{TM} /} \text { Kaneka, } \\
\text { TephaFlex }{ }^{\circledR} / \text { Tepha, } \\
\text { Nodax }^{\mathrm{TM}} / \text { Danimer } \\
\text { Scientific, } \\
\text { AirCarbon }{ }^{\circledR} / \text { Newlight } \\
\text { Technologies }\end{array}$ & $\mathrm{HC}, \mathrm{IC}, \mathrm{AD}, \mathrm{CR}$ \\
\hline PCL & $\begin{array}{c}\text { Chiral hydroxy acids, } \\
\text { lactones }\end{array}$ & -- & $\begin{array}{c}\text { CAPA }^{\mathrm{TM}} / \text { Perstorp } \\
\text { (Ingevity) }\end{array}$ & $\mathrm{HC}, \mathrm{IC}, \mathrm{CR}$ \\
\hline
\end{tabular}




\begin{tabular}{|c|c|c|c|c|}
\hline \multirow[t]{7}{*}{ PBS } & Succinic acid, 1,4- & 97 & GS PLA®/Mitsubishi & $\mathrm{CR}, \mathrm{ED}$ \\
\hline & butanediol & & Chemical, Bionolle $^{\mathrm{TM}}$ & \\
\hline & & & 1000/Showa Denko & \\
\hline & & & K.K., Skygreen®/SK & \\
\hline & & & Chemicals, Succinity, & \\
\hline & & & BioPBS $^{\mathrm{TM}} / \mathrm{PTT}$ MCC & \\
\hline & & & Biochem & \\
\hline \multirow{7}{*}{$\begin{array}{c}\text { PBAT \& PBAT } \\
\text { blends }\end{array}$} & Terephthalic acid, & 152 & Ecoflex ${ }^{\circledR} / \mathrm{BASF}$, & IC, CR \\
\hline & adipic acid & & Wango/Zhuhai Wango & \\
\hline & hydroxymethyl & & Chemical Co., & \\
\hline & furfurals (HMFs), & & Ecoworld/JinHui & \\
\hline & butanediol & & ZhaoLong, Eastar & \\
\hline & & & Bio/Eastman, & \\
\hline & & & Origo-Bi®/Novamont & \\
\hline
\end{tabular}

Bio-based and non-biodegradable polymers

\begin{tabular}{|c|c|c|c|c|}
\hline Bio-PE & $\begin{array}{l}\text { Bioethanol from } \\
\text { sugarcane }\end{array}$ & 200 & Braskem & MR \\
\hline Bio-PET & $\begin{array}{l}\text { Furan dicarboxylic } \\
\text { acid from HMFs }\end{array}$ & 560 & $\begin{array}{c}\text { PlantBottle }{ }^{\mathrm{TM}} / \text { Coca } \\
\text { Cola }\end{array}$ & MR, CR, ED \\
\hline Bio-PTT & 1, 3-propanediol & 45 & $\begin{array}{c}\text { DuPont Corterra }^{\mathrm{TM}} \text {, } \\
\text { Sorona }{ }^{\circledR} / \text { Shell } \\
\text { Chemicals }\end{array}$ & $\mathrm{MR}, \mathrm{CR}$ \\
\hline Bio-PEF & HMFs & - & Synvina/Total-Corbion & ED \\
\hline Bio-PP & Isobutanol & - & Technoform, LanzaTech & $\mathrm{MR}$ \\
\hline Bio-PA & $\begin{array}{c}\text { Volatile fatty acids, } \\
\text { HMFs }\end{array}$ & - & $\begin{array}{c}\text { Evonik VESTAMID® } \\
\text { TERRA, Dupont, FKuR, } \\
\text { BIOFED }\end{array}$ & MR, CR \\
\hline $\begin{array}{c}\text { Bio- } \\
\text { polycarbonates }\end{array}$ & $\begin{array}{l}\text { Bioethanol/dialkyl } \\
\text { carbonate/epoxides } \\
\text { and carbon-dioxide }\end{array}$ & - & $\begin{array}{c}\text { Asahi Kasei Corporation, } \\
\text { Saudi Aramco } \\
\text { Converge }{ }^{\circledR}\end{array}$ & $\mathrm{CR}$ \\
\hline
\end{tabular}

*- Emerging options in bioplastics waste management with either limited or no evidence on technology commercialisation

AD-Anaerobic Digestion; MR- Mechanical Recycling; CR-Chemical/catalytic Recycling; ED-

Enzymatic depolymerisation; IC- Industrial composting HC- Home composting 


\section{State-of-the-art technologies for bioplastics innovations and production}

The current bioplastic sustainable production model relies on design and development of novel valorisation protocols of renewable resources derived from urban, agricultural and food wastes. Approaches to develop monomers and biodegradable polymers from biomass feedstock received great attention in chemical industries by leveraging on the innovative biocatalytic transformation and synthetic chemistry $[25,26]$. Sustainable bioplastics materials are currently under development, and innovation relies either on developing completely new types of polymers or drop-in substitutes derived from renewable resources. Advancements in industrial biotechnology offer various chemo-enzymatic or bio-catalytic synthetic routes for converting biomass or renewable feedstocks into high-value building blocks or monomers [27]. Additionally, engineering of consumer grade bioplastics based on monomers derived from waste residues represents a sustainable production value chain which accounts for establishing circular bioeconomy. Growing global demand for bio-based and biodegradable polymers prompted investments in research to promote and establish large scale production of bioplastics. Bio-based industries (BBI) consortium in partnership with European Union (EU) is investing about 3.7 billion on large scale flagship projects to encourage new technologies for production of bio-based monomers and polymers from waste biomass/renewable feedstock's [28]. As one of the specific impacts of BBI's programme is to replace at least $30 \%$ of fossilbased raw materials with bio-based and biodegradable ones by 2030, potential scope for bioplastics manufacturing processes is foreseen in the coming decade [29].

Bioplastics production by utilising greenhouse gases like carbon dioxide is one of the sustainable carbon upcycling approach which is gaining huge attention [30]. Recent report by Nova Institute has highlighted the projected estimation of directly converting $70 \% \mathrm{CO}_{2}$ for bioplastics manufacturing [31]. Breakthrough research in areas of selective copolymerization process has resulted in the commercial production of polycarbonates constituting about 30-50 wt.\% of waste $\mathrm{CO}_{2}$ [32]. $\mathrm{CO}_{2}$ upcycling efforts are constantly evolving for meeting the predicted demand of producing 450 million tonnes plastic by 2050, which are completely made from renewable carbon [31]. This $\mathrm{CO}_{2}$ recycling approach holds benefit of being easily retrofitted in the fossil-fuel based polymer manufacturing infrastructure thus exerting both economic and environmental benefits. Indeed, lesser dependence of agro-feedstocks, monomer extraction/transformations and complex pre-treatments are considered as highly advantageous against bio-resources derived polymers [33]. 


\section{Sustainability and end-of-life options for bioplastics}

On a global trend, plastic production from fossil-based resources and plastic waste incineration together accounts to about 400 million tonnes of $\mathrm{CO}_{2}$ every year [34]. Replacement of fossil-based plastics with bio-based/biodegradable will certainly reduce carbon footprint at production level. However, assessing its sustainability aspects in terms of end-oflife management is vital to exert bioplastics as an environmentally friendly alternative. Not all bio-based polymers are deemed biodegradable and in contrast some of the biodegradable polymers could also be produced from fossil-based raw materials. Indeed, popularly known bioplastics families like PHB, PCL and starch and their blends are proven to be biodegraded in both managed and specific unmanaged environments [19], however, failing to manage their disposal would result in uncontrolled biodegradation adding to existing plastic pollution [35]. Hence, it is of utmost importance to practice specific end-of-life management considering the properties and processing conditions of each bioplastics rather than a generic waste management plan. Life cycle analysis (LCA) is an indispensable tool to gauge and quantify the benefits or impacts of any bioplastics, subjecting to the boundary conditions and assessment considerations [36].

Despite being resources-efficient and derived from renewable bio-based feedstocks/residues, it is crucial to look closely into environmental impacts of bioplastics waste. Disposal of bioplastics waste in landfill certainly contributes to similar management problems that of conventional plastic waste. Hence, advocating best end-life management of post-consumer bioplastics waste is needed to achieve lower carbon footprint [37]. Sustainable management of bioplastics waste is highly challenging as some of the bioplastics are designed to only biodegrade in specific managed conditions thus creating huge ill-effects when disposed in non-ideal environments like soil, fresh water and marine. Indeed, scientists aim at developing bioplastics that could achieve complete and quicker biodegradation in any environment as per ASTM and ISO standards [38]. However, most of the reported biodegradability of various biodegradable polymers was demonstrated at lab scale and it is essential to establish biodegradation of the commercial bioplastics and their blends at appropriate industrial scale $[39,40]$.

Recycling is considered as the most preferred option to manage bioplastic waste as similar to conventional plastic waste [41]. However, recycling can either be mechanical, chemical/catalytic and organic depending on whether the bioplastics is of biodegradable and/or if the considered polymeric material biodegrades only in managed conditions. The distinct 
recycling options shown in Figure 2 represents the state-of-the-art on closed-loop management of post-consumer bioplastics waste. Prime challenges in recycling of post-consumer bioplastic waste is attributed to its heterogeneity, low market volumes, diverse sources and high potential for plastics waste contamination. These challenges indicate a clear need for more efficient chemical and biochemical processes to valorise the bioplastics waste into perpetually reusable high-value end-products. Implementing combined recycling and recovering concepts including extraction of high-value chemicals/monomers via chemical recycling, solvent extraction [42] and cogeneration of biofuel and volatile fatty acids through anaerobic digestion [43] would certainly create positive impact towards a circular bioeconomy. Perhaps, some of the management approaches would not directly recycle back the bioplastics into its starting monomer. However, it is worthwhile to invest on valorisation of post-consumer bioplastic waste and provide incentives for recycling or energy recovery for contributing to circular bioeconomy and sustainable management of bioplastics waste [44]. 


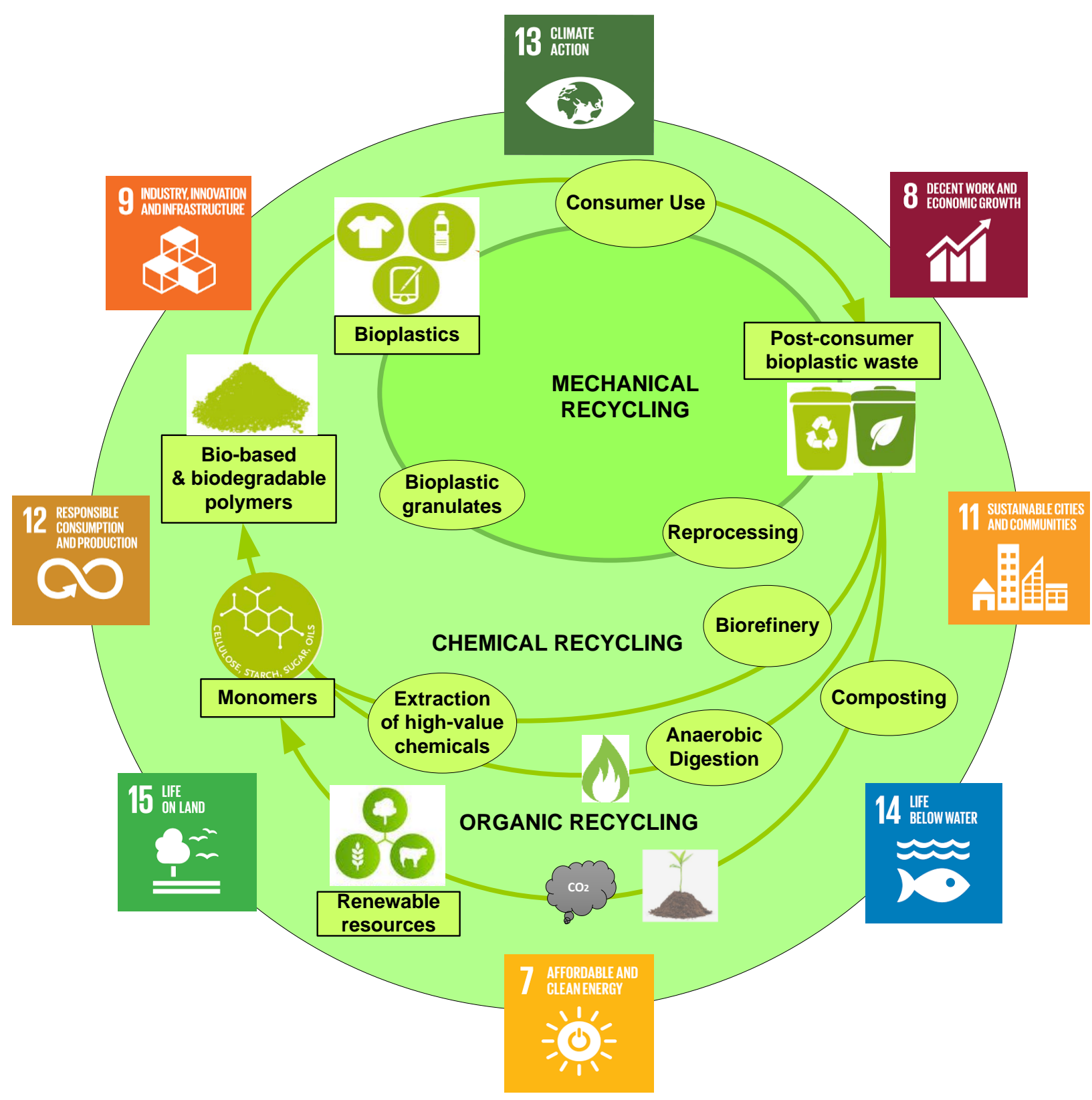

Figure 2. Schematic representation of recycling strategies for sustainable management of bioplastics and contribution towards SDGs

\section{Future outlook}

Rationally designing the bioplastics to impart desired functionality and recyclability $[45,46]$ and utilising unaccounted biomass as a valuable resource would together establish a sustainable production value chain for bioplastics. Despite some of the bioplastics production technologies are lacking the scalability and productivity comparable to petroleum based routes, governmental regulations and consumer pressure has been fostering the bioplastics industry to adopt and implement sustainable production routes. Circular bioeconomy is also gaining global momentum which in turn triggered wide range of stakeholders to leverage the synergistic 
potential of bioplastics manufacturing and upscaling/recycling strategies [47, 48]. Innovations in fundamental redesigning of bioplastics with improved economics for recycling will pave a way for the next generation of sustainable bioplastics.

\section{Acknowledgements}

The authors thank Science Foundation Ireland (SFI) AMBER Grant No: 12/RC/2278_P2 for research support and funding. RB acknowledges the funding support by BEACON Grant No: 16/RC/3889 and also the financial support from BBI-IA-FLAG-Biobased Industries Innovation Action-Flagship-AgriChemWhey project under grant agreement-744310.

\section{References}

Papers of particular interest, published within the period of review, have been highlighted as:

* of special interest

$* *$ of outstanding interest

1. Scalenghe R: Resource or waste? A perspective of plastics degradation in soil with a focus on end-of-life options. Heliyon 2018, 4:e00941.

2. Babu RP, O'Connor K, Seeram R: Current progress on bio-based polymers and their future trends. Progress in Biomaterials 2013, 2:8.

3. Wierckx N, Narancic T, Eberlein C, Wei R, Drzyzga O, Magnin A, et al. Plastic Biodegradation: Challenges and Opportunities. In: Steffan R, editor. Consequences of Microbial Interactions with Hydrocarbons, Oils, and Lipids: Biodegradation and Bioremediation. Cham: Springer International Publishing; 2018. p. 1-29.

4. Spierling S, Knüpffer E, Behnsen H, Mudersbach M, Krieg H, Springer S, et al.: Biobased plastics - A review of environmental, social and economic impact assessments. Journal of Cleaner Production 2018, 185:476-491.

5. ** Karan H, Funk C, Grabert M, Oey M, Hankamer B: Green Bioplastics as Part of a Circular Bioeconomy. Trends in Plant Science 2019, 24:237-249.

This article outlines three phases of advancements in the bioplastic industry which is interesting to know diversified range of resources for biopolymer synthesis. Emerging capabilities of biorefinery and micro-organisms based approaches in producing green bioplastics are highlighted. 
6. Communication From The Commission To The European Parliament, The Council, The European Economic And Social Committee And The Committee Of The Regions-A European strategy for plastics in a circular economy. COM (2018); 2018.

7. Bioplastics market data.https://www.european-bioplastics.org/wpcontent/uploads/2016/02/Report_Bioplastics-Market-Data_2018.pdf

8. Bio-based Building Blocks and Polymers - Global Capacities, Production and Trends 2018-2023.https://european-

biotechnology.com/fileadmin/Content/NewsAndStories/2019/Nova_exec.pdf

9. Pang M-M, Pun M-Y, Ishak ZAM: Degradation studies during water absorption, aerobic biodegradation, and soil burial of biobased thermoplastic starch from agricultural waste/polypropylene blends. Journal of Applied Polymer Science 2013, 129:3656-3664.

10. Khan B, Bilal Khan Niazi M, Samin G, Jahan Z: Thermoplastic Starch: A Possible Biodegradable Food Packaging Material-A Review. Journal of Food Process Engineering 2017, 40:e12447.

11. Endres H, Siebert-Raths A, Behnsen H, Schulz C: Biopolymers facts and statistics. Hanover ISSN 2016:2363-8559.

12. Helanto KE, Matikainen L, Talja R, Rojas OJ: Bio-based Polymers for Sustainable Packaging and Biobarriers: A Critical Review. 2019 2019, 14:4902-4951.

13. Nakajima H, Dijkstra P, Loos K: The Recent Developments in Biobased Polymers toward General and Engineering Applications: Polymers that are Upgraded from Biodegradable Polymers, Analogous to Petroleum-Derived Polymers, and Newly Developed. Polymers 2017, 9:523.

14. Elvers D, Song CH, Steinbüchel A, Leker J: Technology Trends in Biodegradable Polymers: Evidence from Patent Analysis. Polymer Reviews 2016, 56:584-606.

15. European Bioplasticshttps://www.european-bioplastics.org/wpcontent/uploads/2019/11/Report_Bioplastics-Market-Data_2019_short_version.pdf

16. Kawaguchi H, Ogino C, Kondo A: Microbial conversion of biomass into bio-based polymers. Bioresource Technology 2017, 245:1664-1673.

17. * Thakur S, Chaudhary J, Sharma B, Verma A, Tamulevicius S, Thakur VK: Sustainability of bioplastics: Opportunities and challenges. Current Opinion in Green and Sustainable Chemistry 2018, 13:68-75.

This interesting article discusses the sustainable end-of-life options for managing bioplastics. Upcoming challenges and recent trends on recycling with special mention 
on biological routes of recycling opens up new opportunities on bioplastics waste management.

18. ** Hatti-Kaul R, Nilsson LJ, Zhang B, Rehnberg N, Lundmark S: Designing Biobased Recyclable Polymers for Plastics. Trends in Biotechnology 2019.

This interesting article discusses the strategies related to redesigning bio-based polymers. Special focus on biocatalysis brings more insight on emerging recycling and valorisation methods.

19. * Narancic T, Verstichel S, Reddy Chaganti S, Morales-Gamez L, Kenny ST, De Wilde B, et al.: Biodegradable Plastic Blends Create New Possibilities for End-of-Life Management of Plastics but They Are Not a Panacea for Plastic Pollution. Environmental Science \& Technology 2018, 52:10441-10452.

This research article opens up an early step forward to examine the possibilities of biodegradable plastics achieving complete biodegradation under various managed and unmanaged environmental conditions. The authors have examined different blends of biodegradable polymers to highlight specific blends having potential to decompose completely in diversified conditions.

20. Zhang D, Dumont M-J: Advances in polymer precursors and bio-based polymers synthesized from 5-hydroxymethylfurfural. Journal of Polymer Science Part A: Polymer Chemistry 2017, 55:1478-1492.

21. Wu H, Wen B, Zhou H, Zhou J, Yu Z, Cui L, et al.: Synthesis and degradability of copolyesters of 2, 5-furandicarboxylic acid, lactic acid, and ethylene glycol. Polymer Degradation and Stability 2015, 121:100-104.

22. Imre B, Pukánszky B: Compatibilization in bio-based and biodegradable polymer blends. European Polymer Journal 2013, 49:1215-1233.

23. Cheroennet N, Pongpinyopap S, Leejarkpai T, Suwanmanee U: A trade-off between carbon and water impacts in bio-based box production chains in Thailand: A case study of PS, PLAS, PLAS/starch, and PBS. Journal of Cleaner Production 2017, 167:987-1001.

24. ** Niaounakis M: Recycling of biopolymers - The patent perspective. European Polymer Journal 2019, 114:464-475.

This interesting patent review covers the disclosed inventions based on novel recycling technologies of biopolymers which has been patented. As most of the technological advancements are not published in journals but rather reflected in patents, this article summarizes the interesting activities on biopolymers recycling. 
25. Schneiderman DK, Hillmyer MA: 50th Anniversary Perspective: There Is a Great Future in Sustainable Polymers. Macromolecules 2017, 50:3733-3749.

26. Ahmed ST, Leferink NGH, Scrutton NS: Chemo-enzymatic routes towards the synthesis of bio-based monomers and polymers. Molecular Catalysis 2019, 467:95110 .

27. Zhang X, Fevre M, Jones GO, Waymouth RM: Catalysis as an Enabling Science for Sustainable Polymers. Chemical Reviews 2018, 118:839-885.

28. Bio-based Industries - https://www.bbi-europe.eu/projects.

29. Bio-Based Industries Joint Undertaking Investing in the European bioeconomy https://www.bbi-europe.eu/sites/default/files/media/bbi_article_may_2016.pdf

30. * Muthuraj R, Mekonnen T: Recent progress in carbon dioxide (CO2) as feedstock for sustainable materials development: Co-polymers and polymer blends. Polymer 2018, 145:348-373.

This article provides a critical review on progressing methods of producing bio-based polymers from carbon-di-oxide. Specific focus is on the production methodologies of aliphatic polycarbonates, polypropylene carbonates based on $\mathrm{CO}_{2}$ capture.

31. Nova-Institut GmbH, press release, 28 Febraury 2019- http://novainstitute.eu/media/2015/08/18-02-19-nova-company-profile.pdf

32. Markewitz P, Kuckshinrichs W, Leitner W, Linssen J, Zapp P, Bongartz R, et al.: Worldwide innovations in the development of carbon capture technologies and the utilization of CO2. Energy \& Environmental Science 2012, 5:7281-7305.

33. Zhu Y, Romain C, Williams CK: Sustainable polymers from renewable resources. Nature 2016, 540:354.

34. Rahimi A, García JM: Chemical recycling of waste plastics for new materials production. Nature Reviews Chemistry 2017, 1:0046.

35. Ravenstijn J: Bio-Based Polymers: a Revolutionary Change, 2017. Nova-Institute report. Available at http://www.bio-based.eu/reports/

36. Nessi S, Bulgheroni C, Garbarino E, Garcia-Gutierrez P, Orveillon G, Sinkko T, et al. Comparative LCA of alternative feedstock for plastics production - DRAFT FOR STAKEHOLDER CONSULTATION Part II. Joint Research Centre (JRC) Technical Report, European Commission; 2018.

37. Prieto A: To be, or not to be biodegradable... that is the question for the bio-based plastics. Microbial Biotechnology 2016, 9:652-657. 
38. Emadian SM, Onay TT, Demirel B: Biodegradation of bioplastics in natural environments. Waste Management 2017, 59:526-536.

39. Piemonte V, Gironi F: Bioplastics and GHGs Saving: The Land Use Change (LUC) Emissions Issue. Energy Sources, Part A: Recovery, Utilization, and Environmental Effects 2012, 34:1995-2003.

40. Saibuatrong $\mathrm{W}$, Cheroennet $\mathrm{N}$, Suwanmanee $\mathrm{U}$ : Life cycle assessment focusing on the waste management of conventional and bio-based garbage bags. Journal of Cleaner Production 2017, 158:319-334.

41. Hong M, Chen EYX: Future Directions for Sustainable Polymers. Trends in Chemistry 2019, 1:148-151.

42. Tang X, Chen EYX: Toward Infinitely Recyclable Plastics Derived from Renewable Cyclic Esters. Chem 2019, 5:284-312.

43. Albertsson A-C, Hakkarainen M: Designed to degrade. Science 2017, 358:872.

44. Vea EB, Romeo D, Thomsen M: Biowaste Valorisation in a Future Circular Bioeconomy. Procedia CIRP 2018, 69:591-596.

45. Garcia JM, Robertson ML: The future of plastics recycling. Science 2017, 358:870.

46. Narancic T, O'Connor KE: Microbial biotechnology addressing the plastic waste disaster. Microbial Biotechnology 2017, 10:1232-1235.

47. Brockhaus S, Petersen M, Kersten W: A crossroads for bioplastics: exploring product developers' challenges to move beyond petroleum-based plastics. Journal of Cleaner Production 2016, 127:84-95.

48. Hong M, Chen EYX: Chemically recyclable polymers: a circular economy approach to sustainability. Green Chemistry 2017, 19:3692-3706. 